Somatic Cell and Molecular Genetics, Vol. 24, No. 2, 1998, pp. 75-90

\title{
Structural and Functional Analysis of the Protein Products Derived From Mutant fur Alleles in an Endoprotease-Deficient Chinese Hamster Ovary Cell Strain
}

\author{
Joseph F. Sucic, ${ }^{1,2,4}$ Michael J. Spence, ${ }^{1,3}$ and Thomas J. Moehring ${ }^{1}$ \\ 'Department of Microbiology and Molecular Genetics and the Markey Center for Molecular Genetics, and the Vermont \\ Cancer Center, The University of Vermont, Burlington, Vermont 05405
}

Received 26 January 1998-Final 4 June 1998

\begin{abstract}
The fur gene encodes the endoprotease, furin. We recently demonstrated mutations in both fur alleles in the mutant Chinese hamster ovary (CHO)-KI strain, RPE.40, and hypothesized that these mutations were responsible for the endoprotease-deficient phenotype of these cells. We now present the structural and functional properties of three protein products derived from the mutant fur alleles. None of these protein products were able to process the precursor to von Willebrand factor, which is processed by wild-type furin. Pro-protein processing activity initially attributed to one of the mutant proteins was due to wild-type furin produced inadvertently from one of the expression constructs used in these experiments. None of the mutant proteins exhibited evidence of autocatalysis, consistent with the lack of activity versus the test substrate, and glycosylation patterns suggested at least two of them remained in the endoplasmic reticulum. These results confirm that RPE. 40 cells are furin null mutants, as earlier evidence had suggested.
\end{abstract}

\section{INTRODUCTION}

A number of mammalian subtilisin-like endoproteases have recently been discovered (1, 2). The prototype of these enzymes is furin, a calcium-dependent, ubiquitously expressed endoprotease that has been shown to process a number of mammalian pro-proteins, viral glycoproteins, and bacterial toxins at the consensus sequence Arg-X-Lys/Arg-Arg (3-16). Furin is synthesized as an inactive precursor and undergoes autocatalytic activation $(17,18)$. Furin is primarily localized in the trans-Golgi network (TGN) $(4,19-21)$, although it also appears to cycle between the TGN and the cell surface (20); secreted forms of furin, produced by an as yet uncharacterized carboxy-terminal cleavage, have also been identified (20, 22-24).

The physiological role of furin in processing pro-proteins has generated considerable interest. Among the most useful tools used to address this issue have been mutant cell strains that do not express furin. One such cell strain has been developed in our laboratory by mutagenizing Chinese hamster ovary cells (CHO-K1) with ethyl methane sulfonate (EMS). This cell strain, RPE.40, was initially selected for resistance to Pseudomonas exotoxin A

\footnotetext{
${ }^{2}$ Current address: Biology Department, University of Michigan-Flint, Flint, Michigan 48502-2186

${ }^{3}$ Current address: Cancer Research Section, Mountain States Medical Research Institute, Boise, Idaho 83712

${ }^{4}$ To whom correspondence should be addressed: Biology Department, University of Michigan-Flint, 264 MSB, 303 East

Kearsley St., Flint, MI 48502-1950. Telephone: (810) 762-0890 Fax: (810) 762-3387
} 
(PEA; 25). It was subsequently shown that the resistance of RPE. 40 cells to PEA is due to an inability to proteolytically cleave and activate PEA (26). RPE.40 cells are also resistant to several alphaviruses, due to an inability to proteolytically process the viral envelope glycoproteins $(27,28)$. Additionally, RPE.40 cells are unable to process several other precursor proteins, including the endogenous low-densitylipoprotein receptor-related protein and the endogenous insulin proreceptor $(15,29)$. Expression of a mouse furin cDNA in RPE. 40 cells restored wild type characteristics (29, 30). Hybridization of RPE. 40 cells with LoVo cells, endoprotease deficient cells with characterized mutations in their fur alleles $(31,32)$, showed that the lesion(s) in both cell types was in the same genetic locus (26). We therefore concluded that the mutation(s) responsible for the RPE.40 phenotype was at the fur locus.

We recently reported that both $\mathrm{CHO}-\mathrm{K} 1$ and RPE. 40 cells express mRNAs from two fur alleles (33). In CHO-KI cells, the only difference between the two alleles is manifested at codon 196: one allele encodes a cysteine (cys ${ }^{196}$ ) while the other encodes a tyrosine (tyr $\left.{ }^{196}\right)$. The cysteine at position 196 is conserved in all other mammalian furins examined to date $(5,34-40)$, and may be involved in forming a disulfide bridge with cysteine $226(12)$. We hypothesized that the allele encoding cys ${ }^{196}$ produced a functional furin protein, while the functionality of the tyr ${ }^{196}$ protein was suspect. In RPE.40 cells, full length cDNAs encoded only tyr ${ }^{196}$ furins, while cDNAs encoding cys ${ }^{196}$ were synthesized only from mRNAs exhibiting at least two defective exon-splicing patterns, referred to as cys ${ }^{196 d s I}$ and cys ${ }^{196 d s I I}$. Neither defectively spliced mRNA could direct the translation of a full length protein product. We concluded that the tyrosine codon was the result of a pre-existing background mutation found in a subset of CHO-K 1 cells, and the EMS-induced mutation leads to the defective splicing of mRNAs derived from the cysteine encoding allele. We now report that the expression of a full length cDNA encoding cys ${ }^{196}$ in RPE.40 cells resulted in the production of active furin, while the expression of a tyr ${ }^{196}$-encoding cDNA resulted in the production of furin protein unable to process a test substrate. We also show that proteins translated from the defectively spliced mRNAs cannot process a test substrate. We have also examined some other characteristics of these allelic products, including autocatalytic and glycosylation patterns, and showed that the function of the allelic products, or the lack thereof, largely correlates as expected with these characteristics. These results confirm that RPE.40 cells are furin null mutants, as earlier data had suggested.

\section{MATERIALS AND METHODS}

Materials. Tran ${ }^{35}$ S-label was purchased from ICN Biochemicals (Costa Mesa, California). PshAI was purchased from Amersham/ USB (Cleveland, Ohio); all other restriction enzymes were purchased from Gibco-BRL (Gaithersburg, Maryland). Calf intestinal alkaline phosphatase was also purchased from Gibco-BRL. T4 DNA ligase was obtained from Boehringer Mannheim (Indianapolis, Indiana). Western blotting reagents were purchased from Promega (Madison, Wisconsin). The construct encoding the precursor to von Willebrand factor was generously provided by Drs. Jan A. van Mourik and Jan Voorberg of the Central Laboratory of the Netherlands Red Cross Blood Transfusion Service. Unless otherwise indicated, all other reagents were obtained from the Sigma Chemical Company (St. Louis, Missouri).

Cell Culture. CHO-K1 cells were purchased from the American Type Culture Collection (Rockville, Maryland). The generation of RPE.40 cells has been previously described (25). Cells were cultured in Dulbecco's modified Eagle medium/Ham's F-12 medium containing $5 \%$ fetal bovine serum (hereafter referred to as growth medium) at $37^{\circ} \mathrm{C}$ in an atmosphere of $5 \% \mathrm{CO}_{2}$ in air.

Construction of the Expression Plasmids. The PCR amplification and cloning of the furin cDNAs has been described previously (33). The 
cDNAs were cloned into the mammalian expression vector pcDNA3 (Invitrogen; Carlsbad, CA); to simplify terminology, the constructs are referred to in the text by the cDNA they carry, i.e., cys ${ }^{196}$ or cys ${ }^{196 d s I}$. Domain swap constructs were generated by subjecting constructs harboring full length cys ${ }^{196}$ or tyr ${ }^{196}$ cDNAs to digestion with Eco81I and Stul. Two fragments containing codon 196 were recovered and purified following digestion. The Eco81I/ StuI fragments were then reintroduced into the plasmids, but the fragment encoding cys ${ }^{196}$ was inserted into the plasmid originally containing the tyr ${ }^{196}$ codon, while the fragment encoding tyr $^{196}$ was inserted into the plasmid originally containing the cys ${ }^{196}$ codon. Sequencing analysis confirmed the codon present at position 196 in the domain swapped plasmids.

Transfections. Approximately $1 \times 10^{6}$ RPE.40 cells were seeded in $3 \mathrm{ml}$ growth medium in $60 \mathrm{~mm} \times 15 \mathrm{~mm}$ tissue culture dishes and incubated for $16 \mathrm{hr}$ before transfections were initiated. Transfections were done with the Lipofectamine reagent (Gibco-BRL) according to the manufacturer's instructions; 3 $\mu \mathrm{g}$ DNA were used for the transfections, and 3 $\mu \mathrm{g}$ of each construct were used for coexpression experiments. Following transfections, the cells were washed once with Dulbecco's phosphate buffered saline (PBS) and then were incubated in either growth medium (for all radiolabeling experiments) or in HyQ-CCM5 serum-free medium, obtained from Hyclone Laboratories, Inc., Logan, Utah (for coexpression experiments in which the processing of pro-vWF was assayed).

Western Blotting to Analyze pro-vWF Processing. Conditioned HyQ-CCM5 medium from cells co-transfected with the furin and pro-vWF constructs was collected $60 \mathrm{hr}$ post transfection. Samples of the medium were subjected to SDS-PAGE ( $5 \%$ or $7.5 \%$ gels under reducing conditions) and the resolved proteins were transferred to Immobilon-P membranes (Millipore). The membranes were blocked for $1 \mathrm{~h}$ with $2 \%$ milk in PBS, then incubated overnight with anti-vWF antibody (Dako Corpo- ration, Carpinteria, California) diluted 1:2500 in $0.6 \%$ milk-PBS. The membranes were washed $3 \times$ (3 min each) with $0.6 \%$ milk-PBS, blocked for an additional $30 \mathrm{~min}$, and subjected to an anti-rabbit IgG alkaline phosphatase conjugate (diluted 1:5000 in 0.6\% milk-PBS) for $1.5 \mathrm{hr}$. After two more washes in $0.6 \%$ milk-PBS and one in substrate buffer (0.1 M Tris [pH 9.5], 0.1 $\mathrm{M} \mathrm{NaCl}, 5 \mathrm{mM} \mathrm{MgCl}$ ), each for $3 \mathrm{~min}$, color development was initiated by adding 40 ul nitro blue tetrazolium ( $50 \mathrm{mg} / \mathrm{ml}$ ) and $20 \mathrm{ul}$ 5-bromo-4 chloro-3-indolyl-1-phosphate $(50 \mathrm{mg} / \mathrm{ml})$ into $20 \mathrm{ml}$ substrate buffer and placing this mixture on the membrane.

Metabolic Labeling and Immunoprecipitations. Metabolic labeling was used to analyze furin proteins expressed from the recombinant fur cDNAs. Cells transfected with fur constructs were incubated for $40 \mathrm{hr}$ in growth medium, then starved for cysteine and methionine for 30 min in Dulbecco's modified Eagle medium without L-cysteine, L-methionine, or fetal bovine serum (hereafter referred to as labeling medium). This medium was removed and labeling medium containing $200 \mathrm{uCi}{ }^{35} \mathrm{~S}$-amino acids (Tran ${ }^{35} \mathrm{~S}$-label, ICN Biochemicals) per 60 $\mathrm{mm} \times 15 \mathrm{~mm}$ dish was then added. Labelings were done either as pulses or as pulse-chase experiments; for pulse-chase experiments, the labeling medium was removed after the pulse and replaced with growth medium for the chase. The times of pulses and chases varied from experiment to experiment, and the Figure Legends contain information for the individual experiments. Following the labeling, cells were lysed by adding 500 ul Lysis Buffer $(50 \mathrm{mM}$ Tris-HCl [pH 8.0], 0.15 M NaCl, $1 \%$ Triton $\mathrm{X}-100,0.5 \%$ sodium deoxycholate, $0.1 \%$ SDS) per $60 \mathrm{~mm} \times 15 \mathrm{~mm}$ dish and incubating for 10 min on ice. The lysate was centrifuged for $5 \mathrm{~min}$ $(10,000 \times \mathrm{g})$ at $4^{\circ}$ to remove cellular debris. The lysate was precleared by adding $50 \mathrm{ul}$ protein-A-sepharose beads (Sigma) and incubating overnight at $4^{\circ}$ with gentle rocking. Immunoprecipitations were set up on the pre-cleared lysates by adding 2-5 ul of an anti-furin serum, kindly provided by Dr. Steven 
Smeekens and Jane R. Goldman of the Chiron Corporation (Emeryville, California), diluted 1:10 with PBS. The immunoprecipitations were incubated overnight at $4^{\circ}$ with gentle agitation. Protein-A-sepharose was added $(10 \mathrm{ul})$, incubated at $4^{\circ}$ with gentle agitation for $1.5 \mathrm{hr}$, and the beads were pelleted and washed with Lysis Buffer three times. After the third wash, the beads were pelleted again, and immunoprecipitated proteins were eluted from the protein-A/ antibody complex by heating to $95^{\circ}$ for $3 \mathrm{~min}$ in SDS-PAGE sample buffer (41). The eluted proteins were subjected to SDS-PAGE. The gels were stained with Coomassie blue, dried using a Savant gel dryer, and immunoprecipitated proteins were analyzed by autoradiography using Kodak X-ray film. To detect and analyze secreted furin, the immunoprecipitations were carried out on conditioned medium from labeled cells; an equal volume of Lysis Buffer was added to each medium sample prior to preclearing and immunoprecipitation.

Treatment of Furin Proteins with Endoglycosidase $H$ and $N$-Glycanase. All reactions that included endoglycosidase $\mathrm{H}$ and $\mathrm{N}$-glycanase were done on immunoprecipitated furin proteins. Immunoprecipitations were done as described above, except that the immunoprecipitated proteins were not eluted in SDS-PAGE sample buffer. For treatment with N-glycanase, the immunoprecipitated proteins were eluted from the beads by resuspending the beads in 10 ul 0.2 M Tris-HCl (pH 8.0), 0.5\% SDS, $50 \mathrm{mM}$ $\beta$-mercaptoethanol, and heating to $75^{\circ} \mathrm{C}$ for 5 min; 5 ul $7.5 \%$ NP40 were added, the beads were pelleted by pulsing for $5 \mathrm{sec}$ in a microcentrifuge, the supernatant was transferred to a new tube, and $1.2 \mathrm{ul} \mathrm{N}$-Glycanase (Genzyme), corresponding to approximately 0.3 units, were added. The total reaction volume was brought up to $30 \mathrm{ul}$ by the addition of 13.8 ul water, and the reactions were incubated at $37^{\circ}$ for at least $16 \mathrm{hr}$. To treat samples with endoglycosidase $\mathrm{H}$ (endo-H), the immunoprecipitated proteins were eluted from the beads by resuspending the beads in $10 \mathrm{ul} 0.5 \%$ SDS and heating to $75^{\circ} \mathrm{C}$ for $5 \mathrm{~min}$. The beads were then pelleted by pulsing the sample for $5 \mathrm{sec}$ in a microfuge; the supernatant was transferred to a new tube, 19 ul $50 \mathrm{mM}$ sodium phosphate $(\mathrm{pH}$ 6.0) were added, and $1 \mathrm{ul}$ endo-H (Genzyme) was added. The reactions were incubated at $37^{\circ}$ for at least $16 \mathrm{hr}$. After the incubations, SDS-PAGE sample buffer was added, the samples were heated to $95^{\circ} \mathrm{C}$ for $3 \mathrm{~min}$, and then subjected to SDS-PAGE. SDS gels were stained with Coomassie blue, dried, and subjected to autoradiography using Kodak X-ray film. Transferrin and ovalbumin were used as positive controls for $\mathrm{N}-$ Glycanase and endo-H activity, respectively.

\section{RESULTS}

Proprotein Processing Activity of the fur Allelic Products. Figure 1 summarizes the putative fur allelic products produced in RPE.40 cells (33). We cloned cDNAs encoding each of these potential protein products, along with the domain swapped constructs, into the mammalian expression vector pcDNA3. These constructs were co-transfected into RPE.40 cells along with a construct directing the expression of the precursor to von Willebrand factor (pro-vWF). To analyze the processing of the pro-vWF, proteins secreted from transfected cells were analyzed by western blotting, as shown in Fig. 2. Processed VWF was secreted from cells expressing the full length cys ${ }^{196}$ protein, the tyr ${ }^{196} \rightarrow$ cys $^{196}$ protein, and the cys ${ }^{196 d s I}$ protein; pro- $\mathrm{WWF}$ was secreted from cells expressing the tyr ${ }^{196}$, cys ${ }^{196} \rightarrow \mathrm{tyr}^{196}$, and cys ${ }^{196 d s I I}$ proteins. These data suggested that the cys ${ }^{196}$ protein was catalytically active, while the tyr $^{196}$ protein was inactive. Since the results obtained with the domain swap constructs were the same as those obtained with the legitimate cys $^{196}$ and tyr ${ }^{196}$ proteins, the inactivity of furin proteins containing a tyrosine at position 196 is directly attributable to the mutation that changed the cysteine codon at position 196 to a tyrosine codon. Cells transfected with the cys ${ }^{1960 ; \mathrm{I}}$ construct also processed pro-vWF, while cells transfected with the cys ${ }^{196 d s l l}$ construct did not process pro-vWF. The result obtained with cys ${ }^{1964.1}$ was somewhat of a surprise, as we did not expect furin activity to be associated with any of 
A fur cDNA structures

RPE.40 Cys ${ }^{196 d s i}$ cDNA

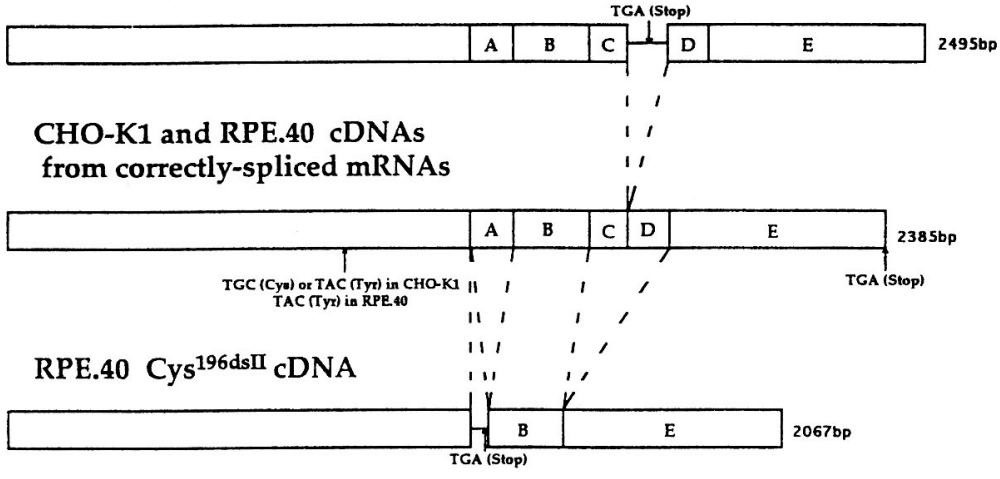

B Protein structures deduced from fur cDNAs

RPE.40 Cys ${ }^{196 d s I}$ furin

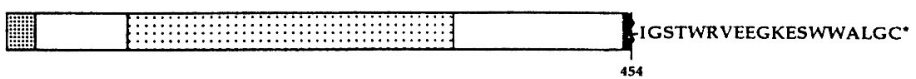

CHO-K1 and RPE.40 furins from correctly-spliced mRNAs

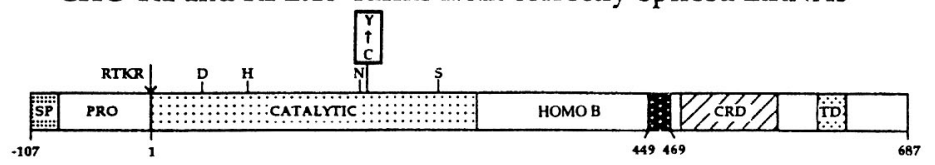

RPE.40 Cys ${ }^{196 d s I I}$ furin

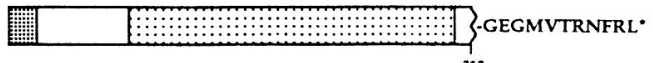

Fig. 1. Summary of the Allelic Products Expressed from the fur Locus in CHO-K1 and RPE.40 Cells. Schematic representation of RPE. 40 and CHO-K1 fur CDNAs and deduced protein structures. (A) The middle structure represents CDNAs derived from correctly spliced mRNAs, while the cys ${ }^{196 d s I}$ and cys ${ }^{196 d s I I}$ cDNAs are shown above and below, respectively. Exons designated A-E represent cDNA segments known to follow proper exon/intron splice junctions; all of the junctions in the CHO-K1 fur gene are not accounted for in the diagrams. Introns, or portions thereof, are shown as straight lines. The sizes of the cDNAs are indicated at the end of each diagram. Location of the translation stop codon (TGA) is indicated for each cDNA. The location of codon 196, encoding either cysteine or tyrosine, is shown in the middle diagram. (B) The deduced furin protein structures are presented in the same order as the cDNA structures. The catalytic and Homo B domains are indicated, while abbreviations are used to designate the signal peptide (SP), pro-peptide (PRO), cysteine-rich domain (CRD), and transmembrane domain (TD). The locations of the active site aspartate, histidine, and serine amino acids, the putative substrate-binding asparagine, and codon 196 are shown within the catalytic domain. The site of autoproteolytic removal of the propeptide is indicated by RTKR. The initiating methionine is designated - 107; the first amino acid in the mature protein is +1 . The blackened area within the Homo B domain represents the region containing amino acids $449-469$, which appear to be essential for furin activity. The total number of exon-encoded deduced amino acids for each furin are indicated. The intron-encoded deduced amino acids are shown extending beyond the diagram of the exon-encoded structures. Reproduced from (33) with permission.

the mutant proteins, given the phenotype of RPE.40 cells and the fact that the cys ${ }^{196 \mathrm{ds}}$ protein lacks an intact Homo B domain, a region of furin proteins believed to be essential for activity.
Structural Analysis of the Full Length Allelic Products. We next turned to an examination of structural characteristics of the furin proteins. We were particularly interested in 


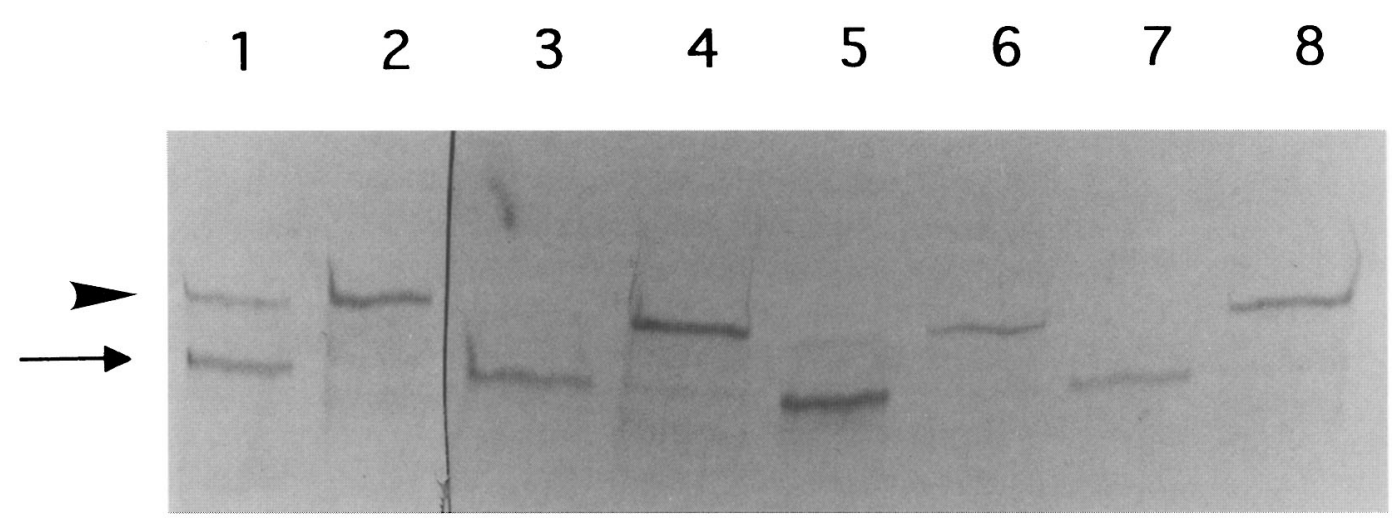

Fig. 2. Coexpression the fur Allelic Products and pro- $\vee W F$ in RPE.40 Cells. Expression vectors carrying cDNAs for the fur allelic products and pro-vWF were introduced into cells following the transfection procedure described in Materials and Methods. At $60 \mathrm{hr}$ post transfection conditioned medium was collected from the transfected cells, and the state of vWF secreted into the medium was analyzed by western blotting. Lanes 1 and 2 are controls in which pro-vWF alone was expressed in either CHO-KI cells (Lane 1) or RPE.40 cells (Lane 2). In the remaining lanes, pro-vWF was coexpressed in RPE.40 cells with constructs directing the expression of full length cys ${ }^{196}$ furin (Lane 3), full length tyr ${ }^{196}$ furin (Lane 4), tyr $^{196} \rightarrow$ cys $^{196}$ furin (Lane 5), cys ${ }^{196} \rightarrow$ yyr $^{196}$ furin (Lane 6), cys ${ }^{196 d x}$ furin (Lane 7), and cys ${ }^{196 d s I l}$ furin (Lane 8 ). The arrowhead indicates the position of pro-vWF, while the arrow indicates the position of mature vWF.

correlating the processing of pro-vWF by the expressed furins with 1) their autocatalytic processing and 2) their pattern of glycosylation, two characteristics which could provide insight into the cellular localization of the furins and the biochemical basis for the processing, or lack thereof, by the furin proteins.

Figure 3 shows the autocatalytic properties of the full length allelic products and the "domain swapped" full length proteins. Autocatalysis was examined by transient transfection, pulse-chase labeling, immunoprecipitation, and SDS-PAGE/autoradiography. Furin proteins containing cys ${ }^{196}$ were immunoprecipitated as a doublet with molecular weights of approximately 100 and $110 \mathrm{kDa}$. This doublet decreased in intensity over the time course of the chase. Furin containing tyr ${ }^{196}$ was immunoprecipitated as a single band that co-migrated with the higher molecular weight member of the cys ${ }^{196}$ doublet and did not decrease in intensity over the time course of the chase. These data suggest the cys $^{196}$ and tyr $^{196} \rightarrow$ cys $^{196}$ proteins underwent autocatalytic processing, indicated by the doublet, and also underwent turnover, as reflected in the decreasing intensity of the bands during the chase period; similar results have been obtained by others examining furin $(12,19,24,42)$. The tyr ${ }^{196}$ proteins did not undergo autocatalysis, as only a single band was observed after immunoprecipitation with anti-furin antibodies. Thus, the substitution of tyrosine for cysteine at position 196 blocked autocatalytic activation. The tyr ${ }^{196}$ proteins also did not turnover, as the $\operatorname{tyr}^{196}$ bands did not decrease in intensity during the time course of the chase. Presumably, the lack of turnover of the tyr ${ }^{196}$ protein is linked to the lack of autocatalysis, as reports suggest profurin molecules remain trapped in the endoplasmic reticulum $(20,23,43)$ and would thus not traverse the same pathway as wild-type furin; we will address this issue below.

Figure 4 shows patterns of glycosylation of the full length allelic products. Radiolabeled cys $^{196}$ or tyr ${ }^{196}$ proteins were immunoprecipitated and then treated with endoglycosidase- $\mathrm{H}$ (endo-H), which removes co-translationally added high mannose sugars, or N-glycanase, which removes all attached sugars, including the endo-H resistant complex oligosaccharides added in the Golgi complex. The treated proteins were then resolved by SDS-PAGE, and the results were visualized by autoradiography. The top panel shows the results obtained with cys ${ }^{196}$ pro- 


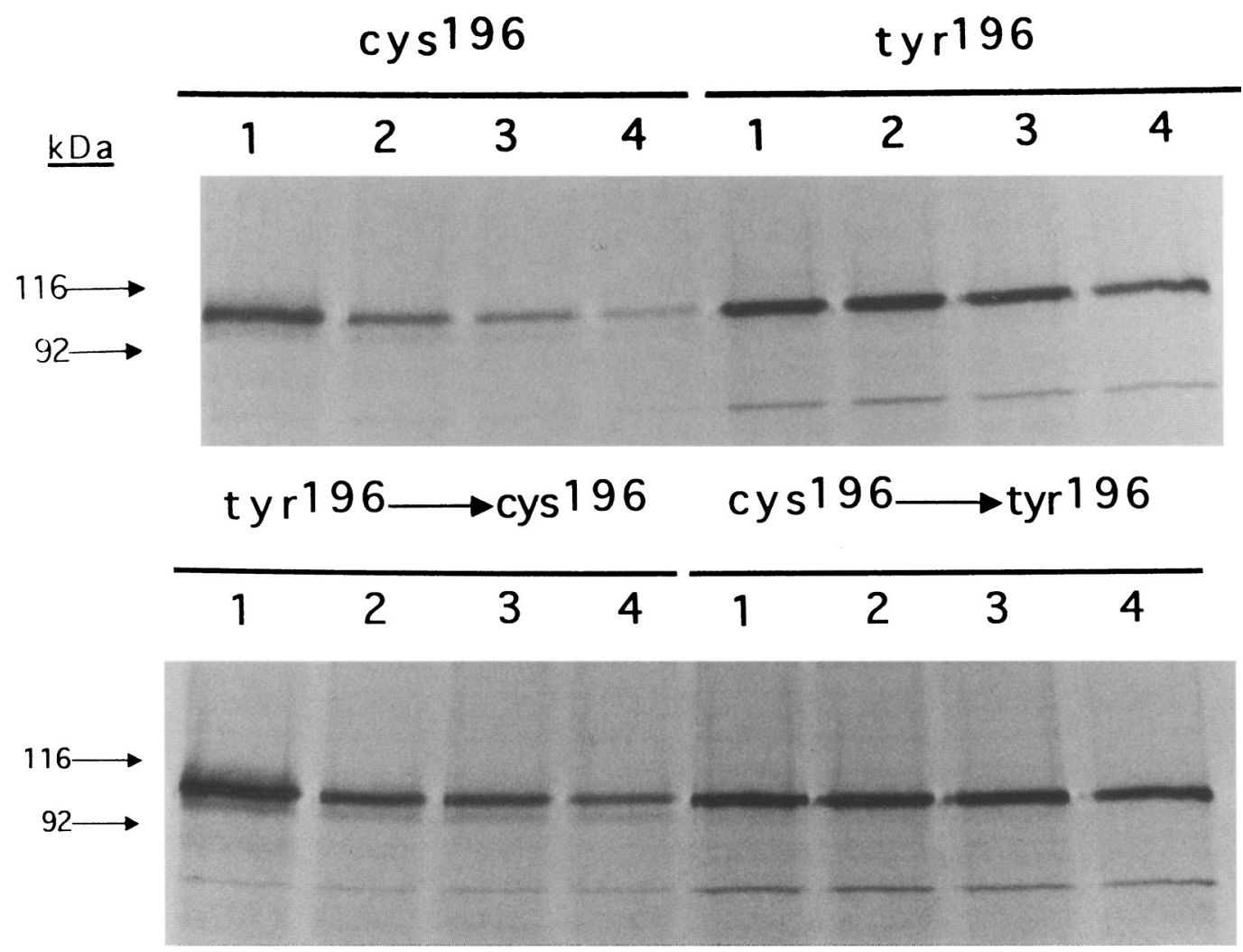

Fig. 3. Analysis of the Autocatalytic Processing of Cys ${ }^{196}$ and Tyr ${ }^{196}$ Full Length Allelic Products. Expression plasmids carrying cDNAs for the cys ${ }^{196}$ and tyr ${ }^{196}$ full length furin products, and the domain swapped cys ${ }^{196} \rightarrow$ tyr $^{196}$ and tyr ${ }^{196} \rightarrow$ cys $^{196}$ furins, were introduced into RPE.40 cells as described in Materials and Methods. At 36 hr post transfection metabolic labeling was initiated; the transfected cells were pulse-labeled for 30 min, followed by chases of $1 \mathrm{hr}, 2 \mathrm{hr}, 3 \mathrm{hr}$, or $4 \mathrm{hr}$ (indicated by $1,2,3$, or 4 ). After the labeling, cells were lysed and furin proteins were immunoprecipitated. The immunoprecipitated proteins were resolved by SDS-PAGE and visualized by autoradiography. The upper panel shows results obtained with the full length cys ${ }^{196}$ furin and full length $\operatorname{tyr}^{196}$ furin. The lower panel shows results obtained with the $\mathrm{tyr}^{196} \rightarrow \mathrm{cys}^{196}$ furin and the cys ${ }^{196} \rightarrow \mathrm{tyr}^{196}$ furin. The arrows indicate the positions of $116 \mathrm{kDa}$ and $92 \mathrm{kDa}$ molecular weight markers. The lower molecular weight protein seen in these figures is non-specifically immunoprecipitated from RPE. 40 cells.

teins. Endo-H treatment separated the cys ${ }^{196}$ doublet into three distinct bands. Based on the results obtained in other studies $(23,43)$, these three bands probably represent (in order of decreasing apparent molecular weight): 1) autocatalytically processed furin that has moved into the Golgi complex and has acquired endo- $\mathrm{H}$ resistant complex oligosaccharides; 2) propeptide containing furin stripped of high mannose sugars by endo- $\mathrm{H}$; and 3 ) autocatalytically processed furin that has not yet moved to the Golgi complex, and thus was stripped of high mannose sugars by endo- $\mathrm{H}$. N-glycanase treatment resolved these three bands into two protein species, which co-migrated with the two lowest molecular weight bands generated by endo- $\mathrm{H}$ treatment. This result is consistent with our interpretation of the endo-H data, since autocatalytically processed, endo-H resistant furin should be sensitive to $\mathrm{N}$-glycanase. The bottom panel shows the results obtained when identical experiments were done on the tyr ${ }^{196}$ protein. The apparent molecular weight of this protein was shifted downward to an equal extent by both endo- $\mathrm{H}$ and $\mathrm{N}$-glycanase treatment, indicating the presence of only high mannose sugars. The data presented in Figure 4 are consistent with our contention that only the cys ${ }^{196}$ protein 


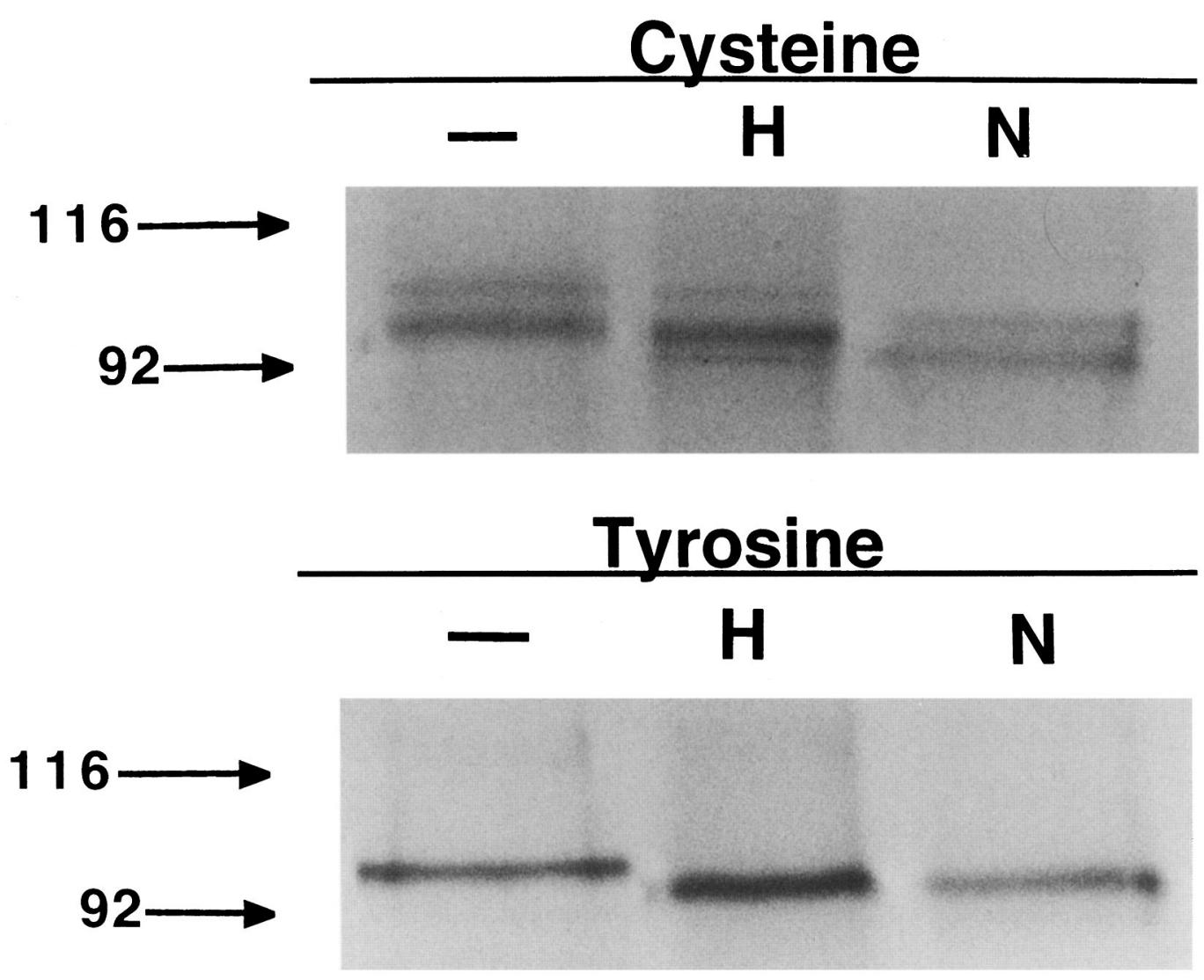

Fig. 4. Glycosylation of the Cys ${ }^{196}$ and Tyr ${ }^{196}$ Furin Proteins. The full length cys ${ }^{196}$ and tyr ${ }^{196}$ containing furins were expressed in RPE. 40 cells as described in Materials and Methods. Proteins were labeled with a $4 \mathrm{hr}$ pulse of ${ }^{35} \mathrm{~S}$-amino acids, then furin proteins were immunoprecipitated and treated with either endoglycosidase $\mathrm{H}$ (endo- $\mathrm{H}$ ), which removes cotranslationally added high mannose sugars from glycoproteins, or $\mathrm{N}$-glycanase, which removes all attached sugar moieties from glycoproteins. The treated proteins were resolved by SDS-PAGE and visualized by autoradiography. Lanes marked represent untreated controls. Lanes labeled $\mathrm{H}$ represent samples treated with endo- $\mathrm{H}$, while Lanes marked $\mathrm{N}$ contain samples treated with $\mathrm{N}$-glycanase. The identity of the amino acid at position 196 is indicated as either cysteine or tyrosine. The arrows indicate the positions of $116 \mathrm{kDa}$ and $92 \mathrm{kDa}$ molecular weight markers.

moves from the endoplasmic reticulum to the Golgi complex, as only this protein acquired the complex oligosaccharides added in the Golgi complex. The results shown in Fig. 4 are also consistent with our hypothesis that only the cys ${ }^{196}$ protein undergoes autocatalytic activation. Results of experiments in which the domain swapped products were subjected to endo- $\mathrm{H}$ and $\mathrm{N}$-glycanase treatment were identical to the results obtained with the "original" proteins; only proteins containing cys 196 exhibited evidence of autocatalysis and endo- $\mathrm{H}$ resistance (data not shown).
Structural Analysis of the cys ${ }^{196 d s l}$ and cys $^{\text {196dsll }}$ Proteins. Figure 5 shows the results of our initial examination of the autocatalytic properties of the cys ${ }^{196 d s 1}$ and cys ${ }^{196 d s I I}$ proteins. These proteins were analyzed by transient transfection and metabolic labeling, as described for the full length proteins above. However, because the truncated proteins resulting from the translation of the defectively spliced mRNAs would lack a transmembrane domain (Fig. 1), and because such furins can be secreted $(7,42)$, cell lysates as well as conditioned media were examined for the 


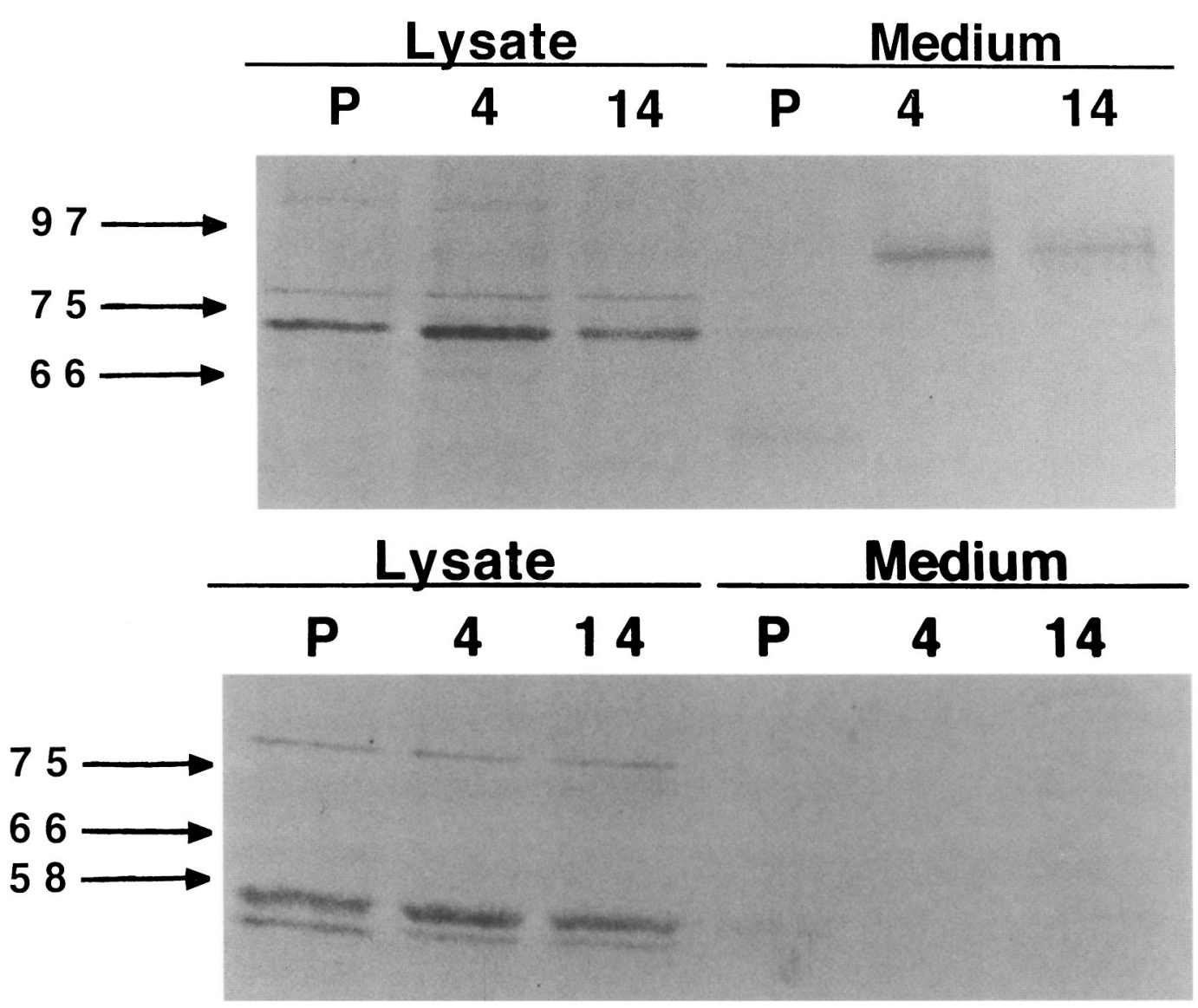

Fig. 5. Examination of the Autocatalytic Properties of the Cys ${ }^{196 d s I}$ and Cys ${ }^{196 d s I I}$ Furin Proteins. The cys ${ }^{196 d s I}$ and cys ${ }^{196 d s I I}$ proteins were expressed in RPE.40 cells as described in Materials and Methods. Proteins were labeled with a 30 min pulse of ${ }^{35} \mathrm{~S}$-labeled amino acids followed by a chase of either $4 \mathrm{hr}$ or $14 \mathrm{hr}$. Furin proteins were then immunoprecipitated from either cellular lysates or samples of conditioned medium. The upper panel shows results obtained with the cys ${ }^{196 d s I}$ protein; the lower panel shows results obtained with the cys ${ }^{196 d s ! 1}$ protein. Immunoprecipitations were done from lysates or medium, as indicated. Lanes labeled $P$ were immunoprecipitated from samples pulse labeled for $30 \mathrm{~min}$. Lanes labeled 4 were immunoprecipitated from samples chased for $4 \mathrm{hr}$ after the $30 \mathrm{~min}$ pulse. Lanes labeled 14 were immunoprecipitated from samples chased for $14 \mathrm{hr}$ after the $30 \mathrm{~min}$ pulse. Arrows represent the positions of molecular weight markers. The protein just above the $75 \mathrm{kDa}$ marker is non-specifically immunoprecipitated from RPE.40 cells.

presence of furin proteins in these experiments. Immunoprecipitations from lysates derived from cells transfected with the cys ${ }^{196 d s I}$ construct exhibited a prominent band of approximately 72 $\mathrm{kDa}$, while immunoprecipitations from lysates derived from cells expressing cys ${ }^{196 d s I}$ showed a doublet with bands of approximately 50 and 54 $\mathrm{kDa}$. These results suggest the truncated furins do not undergo autocatalytic activation, for no doublet was observed for the cys ${ }^{196 \mathrm{ds}}$ protein and the size heterogeneity observed for the cys $^{196 d s I I}$ doublet was not sufficient to be attributed to propeptide removal. Also, the observed molecular weights approximate the calculated molecular weights determined for cys $^{196 \mathrm{dsI}}(75 \mathrm{kDa})$ and cys ${ }^{196 \mathrm{dsII}}(56 \mathrm{kDa})$ proteins with propeptides. Analysis of medium samples from cells transfected with the cys ${ }^{196 d s l}$ plasmid revealed a protein of approximately $85 \mathrm{kDa}$, suggesting a form of secreted furin was produced by these cells. The medium from cells transfected with pcDNA3-cys ${ }^{196 d s I I}$ showed no 
proteins immunoprecipitated by the anti-furin antibodies, indicating that no secreted form of furin was produced by these cells.

The results obtained with cys ${ }^{196 d s I}$ raised some obvious concerns. First, we saw no evidence of autocatalytic activity in the immunoprecipitated cys ${ }^{196 \mathrm{dsI}}$ protein, as only a single band was observed. We had expected to see evidence of autocatalysis, since coexpression of the cys ${ }^{196 d s I}$ protein with pro-vWF had resulted in the production of mature vWF (Fig. 2). Second, the protein immunoprecipitated from medium samples was almost $15 \mathrm{kDa}$ larger than the protein observed in the cell lysates. While glycosylation can increase the apparent molecular weight of a protein, a nearly $15 \mathrm{kDa}$ shift seemed unreasonable considering that the complete glycosylation of full length furin results in an apparent molecular weight increase of 10 $\mathrm{kDa}$ or less $(23,42$, Fig. 4). These inconsistencies led us to reevaluate some of our data and materials. The nature of the cDNA used to make the cys ${ }^{196 \mathrm{ds}}$ expression construct quickly became a source of concern. This cDNA was made from the defectively spliced cys ${ }^{196 d s I} \mathrm{mRNA}$ and contains the sequence of the intact, normal intron inserted between what we have designated furin exons $\mathrm{C}$ and $\mathrm{D}$ (Fig. 1). We speculated that at least some of the RNA transcribed from this construct might have the intron properly removed, resulting in the correct splicing of a full-length, cys ${ }^{196}$ furin mRNA in the transfected cells. Indeed, the cys ${ }^{196 d s I}$ lysate immunoprecipitations in Fig. 5 show what could be a full length furin doublet running at approximately $100 \mathrm{kDa}$. We further speculated that if some correct splicing of these mRNAs was occurring, then 1) the pro-vWF processing activity we had observed in the cys ${ }^{190 d s}$ transfectants was the result of full-length, cys ${ }^{196}$ furin, and 2) the $85 \mathrm{kDa}$ protein observed in the medium from these transfected cells was soluble furin, presumably derived from a carboxyterminal truncation of full length furin molecules $(18,20,22-24)$. We tested these hypotheses as described below.

To examine whether some full length furin protein was being synthesized, truncated, and secreted from cells transfected with the cys ${ }^{196 \mathrm{~d} .1}$ construct, we carried out a transfection and labeling experiment to compare the products derived from both cys ${ }^{196}$ and cys ${ }^{196 d s l}$ constructs. We examined furin proteins in both the lysates and in the medium from these transfected cells, and examined their glycosylation characteristics. These results are shown in Fig. 6. The cells transfected with the cys ${ }^{196 \mathrm{ds} I}$ expression plasmid clearly produce two furin proteins. The larger of these proteins co-migrates as a doublet with the full-length furin doublet derived from cells expressing the cys ${ }^{196}$ furin. The $85 \mathrm{kDa}$ protein immunoprecipitated from the conditioned medium of cells transfected with the cys ${ }^{196 d s i}$ construct co-migrates with a protein derived from the conditioned medium of cells expressing the cys ${ }^{196}$ protein. These data provided strong evidence that some of the mRNA transcribed from the cys ${ }^{196 d s i}$ construct was being correctly spliced, and suggested that the activity we had attributed to the cys ${ }^{196 d s}$ protein is the result of full length furin derived from a population of correctly spliced mRNAs in the cys ${ }^{196 \mathrm{ds} I}$-transfected cells.

To prove that full length furin molecules produced by cells transfected with the cys ${ }^{196 x \mathrm{~s} I}$ construct were the result of correctly spliced mRNAs, we created an alternate expression plasmid in which the intact intron was removed. The generation of the alternate construct is shown in Figure 7. Briefly, the original cys ${ }^{196 d s 1}$ expression plasmid was digested with PshAI, an enzyme which cut the construct just downstream of the stop codon encoded in the intron, and EcoRV, which cut in the multiple cloning site of pcDNA3 just downstream of the cloned cDNA. Both of these restriction enzymes generate blunt ends, and the construct was religated following a gel purification step to remove the small fragment containing the $3^{\prime}$ intron and cDNA sequences. The resultant plasmid contained all of the sequence information necessary to make the truncated cys ${ }^{196 d s I}$ protein, but lacked the complete intron sequence and the $3^{\prime}$ end of the full length cDNA contained in the original 


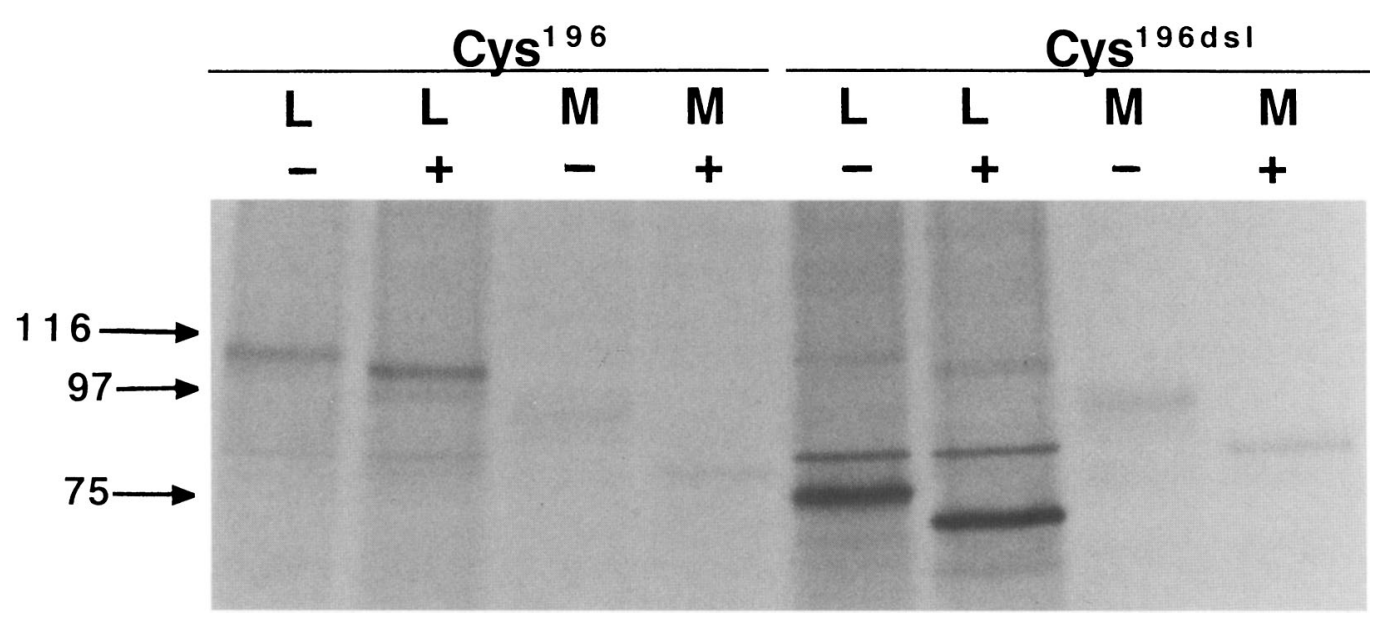

Fig. 6. Comparison of Proteins Expressed from Plasmids Encoding the Cys ${ }^{196}$ and Cys ${ }^{196 d s t}$ Furins. Expression plasmids encoding either the full length cys ${ }^{196}$ furin or the cys ${ }^{196 d s I}$ furin were introduced into RPE.40 cells. Expressed furin proteins were labeled for $16 \mathrm{hr}$ with ${ }^{35} \mathrm{~S}$-labeled amino acids and immunoprecipitated from either cell lysates (L) or conditioned medium (M). One sample of each immunoprecipitate was treated with $\mathrm{N}$-Glycanase $(+)$, while a second was untreated $(-)$. The arrows represent the positions of molecular weight markers. The protein just above the $75 \mathrm{kDa}$ marker is non-specifically immunoprecipitated from RPE. 40 cells.

construct. The nomenclature assigned to the new construct and its cDNA was cys ${ }^{196 d s i-a}$. Furin proteins expressed from this construct were then analyzed by transfection and metabolic labeling, and compared to the furin proteins expressed from the cys ${ }^{190 \mathrm{dsl}}$ construct. These results are shown in Figure 7 (middle panel). The cys ${ }^{196 d s-a}$ construct directed the synthesis of a $72 \mathrm{kDa}$ protein found only in the lysate. Full length furin proteins and the $85 \mathrm{kDa}$ medium protein were expressed only in cells transfected with the cys ${ }^{196 d s I}$ construct, as hypothesized. We then examined the ability of the truncated protein expressed from the cys ${ }^{196 d^{d s-a}}$ construct to process pro-vWF. Figure 7 (bottom panel) shows that cells co-transfected with cys ${ }^{196 d s I-a}$ and the pro-vWF expression plasmid secreted only pro-vWF, while cells co-transfected with the cys ${ }^{196 d s}$ and pro-vWF constructs secreted mature vWF. Figures 6 and 7 thus provide conclusive evidence that: 1) the activity we had earlier attributed to the cys ${ }^{196 d s l}$ protein was in fact due to full length, cys ${ }^{196}$ furin translated from correctly spliced mRNAs derived from the cys ${ }^{196 d s I}$ construct; 2) the $72 \mathrm{kDa}$ protein represents the translation product of legitimate cys ${ }^{196 \mathrm{ds}}$ mRNAs; and 3) the $72 \mathrm{kDa}$ protein is not catalytically active.

To further analyze the cys ${ }^{196 d s I}$ (expressed from the cys ${ }^{196 d s-a t}$ construct) and cys ${ }^{196 d s i l}$ proteins we examined their glycosylation characteristics (Fig. 8). Endo-H treatment indicated both proteins contained high mannose oligosaccharides. The shift in molecular weight was less than that obtained with endo-H treatment of full length furin molecules, indicative of the likely loss of glycosylation sites in the truncated proteins (Fig. 1). The cys ${ }^{196 d s I I}$ doublet is apparently the result of inconsistent addition of high mannose sugars to individual protein molecules, as the endo- $\mathrm{H}$ treatment abolishes the size heterogeneity observed in the immunoprecipitated protein. $\mathrm{N}$-glycanase treatment of the cys ${ }^{196 \mathrm{dsI}}$ protein caused a larger molecular weight shift than treatment with endo- $\mathrm{H}$, suggesting that complex oligosaccharides are a component of this protein's complement of sugars. This result was somewhat unexpected, but may be attributable to the nature of the cys ${ }^{196 \mathrm{ds}}$ molecule (discussed further). The apparent molecular weight of the cys ${ }^{196 d s I I}$ protein is identically altered by both endo- $\mathrm{H}$ and 


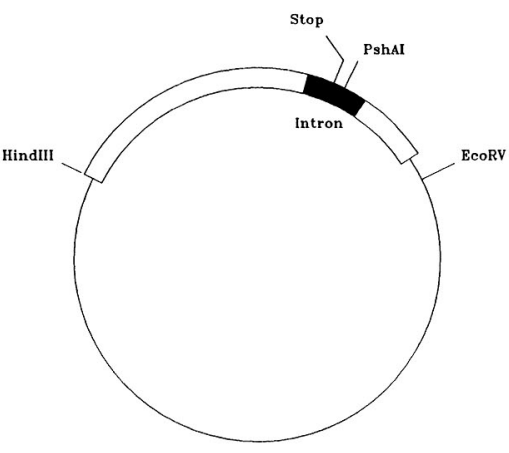

peDNA3-cys ${ }^{198 d e r}$

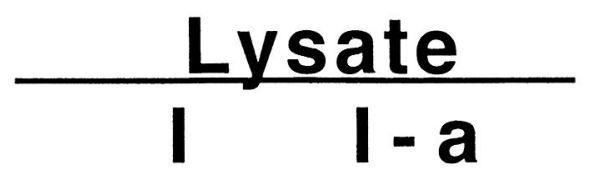

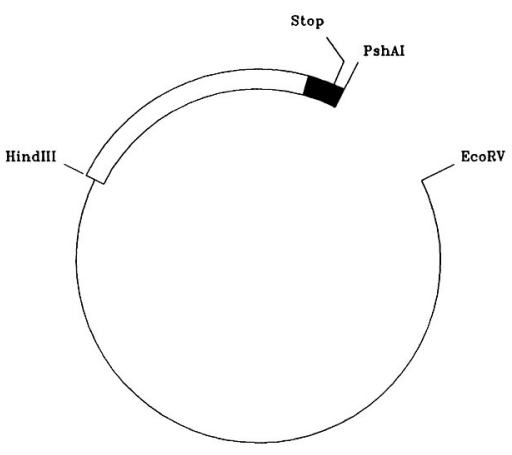

Religate to form pcDNA3-cys ${ }^{\text {196dsI-q }}$

\section{Medium}

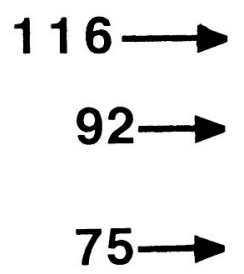

1

2

3

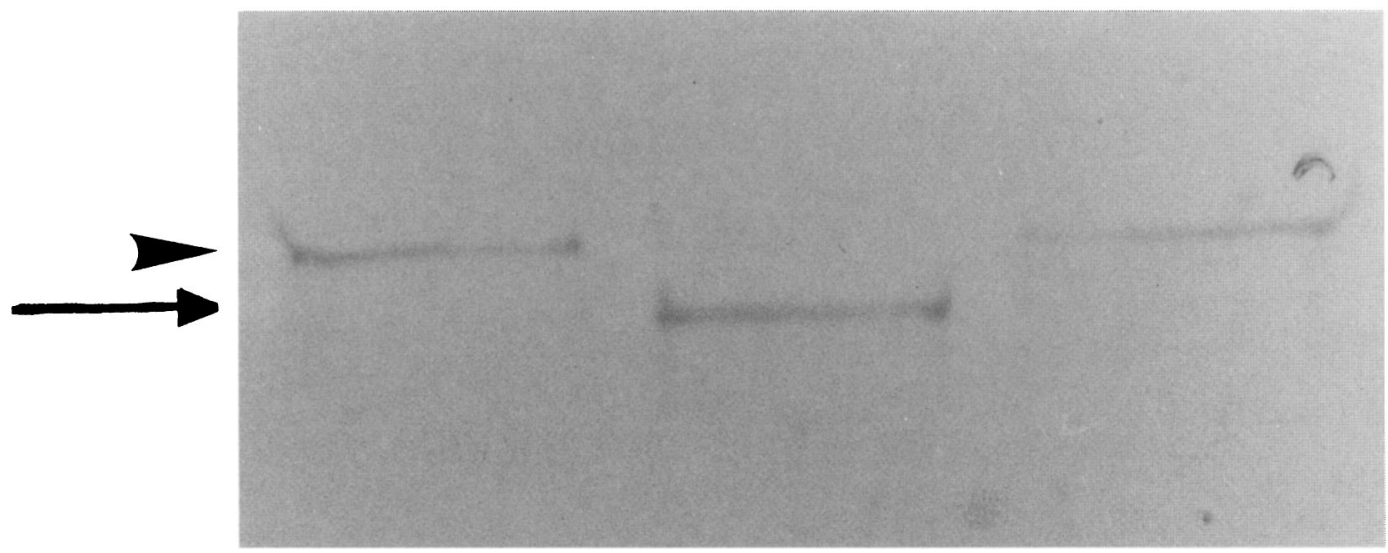

Fig. 7 


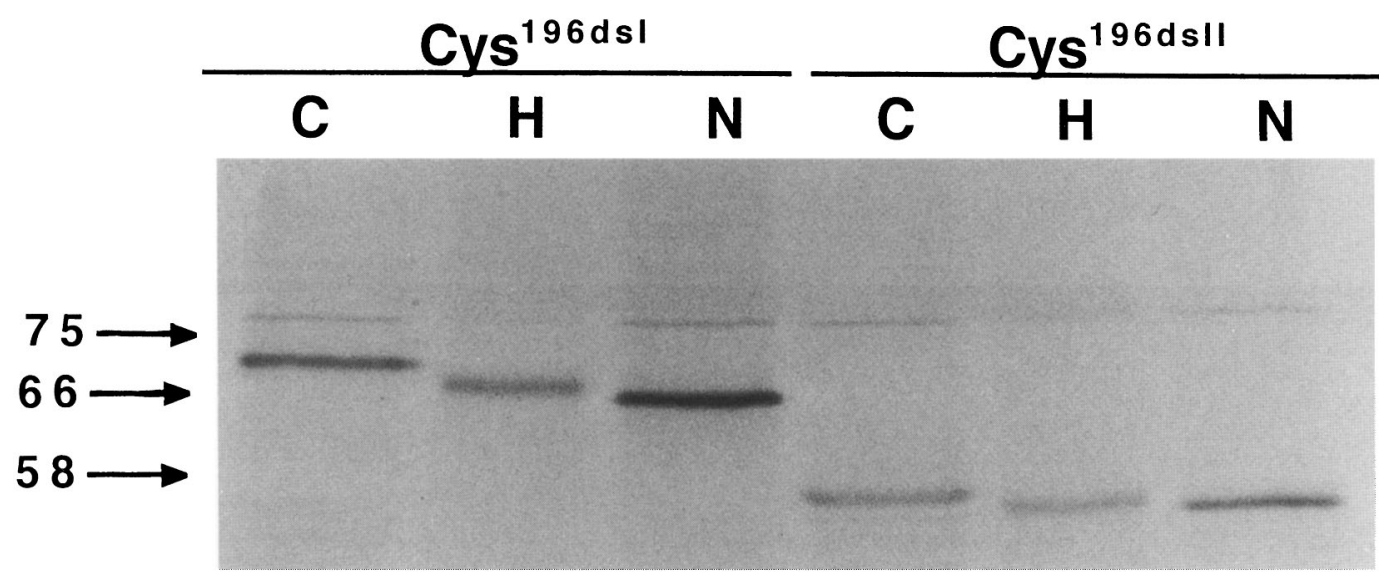

Fig. 8. Glycosylation of the Cys ${ }^{196 d s l}$ and Cys ${ }^{196 d s I I}$ Furin Proteins. RPE.40 cells were transfected with expression plasmids encoding either the cys ${ }^{196 \mathrm{dsI}}$ (the cys ${ }^{196 \mathrm{ds}-\mathrm{a}}$ construct) or cys ${ }^{196 \mathrm{dsII}}$ proteins. Proteins were labeled with ${ }^{35} \mathrm{~S}$-amino acids $36 \mathrm{hr}$ post transfection, and furin proteins were immunoprecipitated from cell lysates. Samples of each immunoprecipitated protein were treated with endo $\mathrm{H}$ (lanes marked $\mathrm{H}$ ) or $\mathrm{N}$-glycanase (lanes marked $\mathrm{N}$ ); samples in lanes marked with a $\mathrm{C}$ were untreated controls exposed to neither enzyme. Results were analyzed by SDS-PAGE and autoradiography. Arrows mark the positions of the indicated molecular weight standards. The protein just above the $75 \mathrm{kDa}$ marker is non-specifically immunoprecipitated from RPE.40 cells.

$\mathrm{N}$-Glycanase, indicating only high mannose sugar groups are attached to this molecule.

\section{DISCUSSION}

RPE. 40 cells are deficient in an endoprotease activity. We have compiled considerable evidence indicating that the genetic lesion(s) in these cells are in both alleles of the fur gene (29, 30,33 ). We recently demonstrated that two fur alleles are expressed in RPE.40 cells and showed that each allele in these cells harbors a mutation (33). In one allele, a background point mutation results in a tyrosine codon rather than the wild-type cysteine codon at position 196. The other allele encodes cysteine at position 196, but an unidentified EMS-generated point mutation causes the defective splicing of mRNAs. The defectively spliced mRNAs can be translated into truncated furin proteins. In this study, co-expression experiments were utilized to demonstrate that furin proteins manifesting these mutations are not catalytically active. This finding conclusively proves that RPE.40 cells are furin null mutants. Our studies, and those of others, provide insight into the underlying

Fig. 7. Preparation of the Cys ${ }^{196 \mathrm{ds} s-a}$ Construct and Analysis of the Protein(s) Expressed From This Construct. The top panel shows the construction of the cys $196 \mathrm{dsl}-\mathrm{a}$ expression plasmid. In the middle panel, the distribution of the protein expressed from this construct was examined by labeling transfected cells and immunoprecipitating furin proteins from cellular lysates and conditioned medium, as indicated; as a control, parallel experiments were done using the original cys ${ }^{196 d s I}$ construct. Lanes labeled I were immunoprecipitated from cells transfected with the cys ${ }^{196 \mathrm{dsI}}$ construct. Lanes labeled I-a were immunoprecipitated from cells transfected with the cys ${ }^{196 d s-a}$ construct. Arrows indicate the positions of molecular weight markers. The protein just above the $75 \mathrm{kDa}$ marker is non-specifically immunoprecipitated from RPE. 40 cells. In the bottom panel, the pro-vWF processing activity of cells co-transfected with the cys ${ }^{196 d s-a}$ and pro-yWF constructs was examined; parallel co-transfections were done using the original cys ${ }^{196 d s 1}$ construct and the pro-vWF construct. Samples of conditioned medium from the transfected cells were collected $60 \mathrm{hr}$ post transfection and the processing of pro-vWF analyzed by western blotting. Lane 1 is a control, in which pro-vWF alone was expressed in RPE.40 cells. In Lanes 2 and 3 pro-vWF was coexpressed in RPE.40 cells along with either the proteins produced from the original cys ${ }^{196 d s 1}$ construct (Lane 2) or the protein made from the cys ${ }^{196 \mathrm{ds} I-\mathrm{a}}$ construct (Lane 3). The arrowhead indicates the position of pro-vWF, while the arrow indicates the position of mature vWF. 
biochemical basis for the lack of activity in the mutant proteins. Amino acid 196 is located in the heart of the catalytic domain of mammalian furins, and the cysteine at position 196 is conserved in all mammalian furins $(5,34-40)$. Molecular modeling studies have led to the hypothesis that either cys ${ }^{196}$ or cys ${ }^{198}$ forms a disulfide bridge with $\operatorname{cys}^{226}$ (12). The disruption of this disulfide bridge could seriously alter the three dimensional configuration of the active site, and therefore could impact the ability to bind substrate and/or engage in catalysis. Our data are consistent with this model, although further studies are needed to conclusively say this disulfide bridge is disrupted in the tyr ${ }^{196}$ furin. We can, however, unequivocally conclude that cys ${ }^{196}$ plays some essential role in the catalytic activity of furin, as we had postulated (33).

Although the truncated cys ${ }^{196 d^{2 s}}$ and cys ${ }^{196 d s l}$ proteins retain a wild type catalytic domain, neither contains an intact Homo B domain. It has been suggested that furin proteins lacking an intact Homo B domain fail to fold into the proper three dimensional configuration (42). Other studies on mammalian furins truncated into the Homo B domain suggest that the region containing amino acids $449-469$ of mature furin is essential for catalytic activity, perhaps reflecting a requirement for this region in the proper folding of the protein $(7,31,42)$. The furin amino acid sequence encoded by the cys ${ }^{190 d s I}$ cDNA terminates at position 454 . The lack of catalytic activity of this truncated molecule may indicate that an amino acid necessary for proper folding and activity is located between position 454 and 469; however, the presence of 19 intron-encoded amino acids at the carboxy terminus of the cys ${ }^{196 d s i}$ protein introduces another variable, and makes a definitive conclusion about the importance of amino acids 454-469 somewhat problematic. The cys ${ }^{196 \mathrm{ds} \text { II }}$ protein is truncated at position 312 , and, thus, the lack of catalytic activity was expected.

We examined other characteristics of the mutant proteins and compared these features to those of the wild-type, cys ${ }^{196}$ furin. None of the mutant proteins exhibited evidence of autocatalytic activity. This observation is consistent with their inability to process pro-vWF. Others have identified a mutant furin capable of autocatalysis while exhibiting no catalytic activity versus pro-vWF (42). In this mutant protein, Asn ${ }^{188}$, a residue believed to be important in substrate binding, was changed to an alanine residue by site directed mutagenesis. The lack of catalytic activity versus pro-vWF in this mutant enzyme is presumably due to an inability to bind substrate molecules. None of the mutant furins we have examined appears to be like the Ala ${ }^{188}$ furin in this regard, as the lack of processing activity versus pro-vWF correlates with a lack of autocatalytic processing.

We also examined the glycosylation of the mutant proteins. The tyr ${ }^{196}$ furin did not acquire endo-H resistance, indicating that no complex oligosaccharides were attached to this protein. This finding suggests that the $\operatorname{tyr}^{196}$ protein remains in the endoplasmic reticulum, and is consistent with reports showing that furin molecules containing the pro-peptide remain in this compartment $(20,23,43)$. The glycosylation characteristics of the cys ${ }^{196 d s 1}$ and cys ${ }^{196 d s I I}$ proteins proved somewhat more difficult to interpret, and conclusions about their cellular localization are more problematic. Truncated furin proteins would not be expected to localize in the TGN, as the carboxy terminus appears to mediate this localization $(24,44-46)$, and several truncated mammalian furins have been shown to be secreted $(7,42)$. However, severely truncated furins are not secreted; furin proteins of at least 475 amino acids in length appear to be secreted, while shorter furins ( 303 amino acids or shorter) exhibit no evidence of secretion (7, 42). We found no evidence for secretion of the cys ${ }^{196 d s i}$ protein, which is truncated at amino acid position 454 but also contains 19 intron coded amino acids at the carboxy terminus. Interestingly, the cys ${ }^{196 \mathrm{dsl}}$ protein did appear to acquire endo-H resistance, suggesting this protein does move out of the endoplasmic reticulum. That the cys ${ }^{1 \% \% d s i 1}$ protein was not secreted was not surprising considering the results of 
others examining similar severely truncated furin proteins (42). The glycosylation characteristics of this protein, while somewhat unusual, suggest it remains in the endoplasmic reticulum; the apparently variable glycosylation we observed may be a manifestation of the aberrant nature and severe truncation of this protein.

Our initial co-expression experiments suggested the cys ${ }^{196 \mathrm{dsI}}$ protein was catalytically active. We subsequently showed that this activity was due to the presence of some correctly spliced furin mRNAs being produced and translated into full-length, catalytically active furins. The correctly spliced mRNAs arose when the intact intron contained within our initial cys ${ }^{196 d s I}$ cDNA was properly excised. Correct removal of the intron apparently occurs only in a subset of the RNA population transcribed from the cys ${ }^{196 d s i}$-encoding plasmid, and we have not yet established a mechanism to explain why the intron is removed in only some of the RNAs.

\section{ACKNOWLEDGMENTS}

This research was supported by National Institutes of Health Grant AI 09100 and the Lucille P. Markey Charitable Trust. The authors thank Holly R. Benisek and Maria V. Badin for critically reviewing the manuscript, and Jason J. Taylor for assistance with Figure 7.

\section{LITERATURE CITED}

1. Barr, P.J. (1991) Cell, 66:1-3.

2. Steiner, D.F., Smeekens, S.P., Ohagi, S., and Chan, S.J. (1992). J. Biol. Chem., 267:23435-23438.

3. Bravo, D.A., Gleason, J.B., Sanchez, R.I., Roth, R.A. and Fuller, R.S. (1994). J. Biol. Chem., 269:2583025837.

4. Bresnahan, P.A., Leduc, R., Thomas, L., Thorner, J., Gibson, H.L., Brake, A.J., Barr, P.J. and Thomas, G. (1990). J. Cell. Biol., 111:2851-2859.

5. Hatsuzawa, K., Hosaka, M., Nakagawa, T., Nagase, M., Shoda, A., Murakami, K., and Nakayama, K. (1990). J. Biol. Chem., 265:22075-22078.

6. Hatsuzawa, K., Nagahama, M., Takahashi, S., Tokoda, K., Murakami, K., and Nakayama, K. (1992). J. Biol. Chem., 267:16094-16099.

7. Hatsuzawa, K., Murakami, K., and Nakayama, K. (1992). J. Biochem., 111:296-301.
8. Hosaka, M., Nagahama, M., Kim, W.-S., Watanabe, T., Hatsuzawa, K., Ikemizu, J., Murakami, K., and Nakayama, K. (1991). J. Biol. Chem., 266:1212712130 .

9. Klimpel, K.R., Molloy, S.S., Thomas, G., and Leppla, S.H. (1992). Proc. Narl. Acad. Sci. U.S.A., 89:1027710281 .

10. Molloy, S.S., Bresnahan, P.A., Leppla, S.H., Klimpel, K.R., and Thomas, G. (1992). J. Biol. Chem., 267:16396-16402.

11. Stieneke-Grober, A., Vey, M., Angliker, H., Shaw, E., Thomas, G., Roberts, C., Klenk, H.-D., and Garten, W. (1992). EMBO J., 11:2407-2414.

12. Van de Ven, W.J.M., Voorberg, J., Fontijn, R., Pannekoek, H., Van den Ouweland, A.M.W., Van Duijnhoven, H.L.P., Roebroek, A.J.M., and Siezen, R.J. (1990). Mol. Biol. Rep., 14:265-275.

13. Wasley, L.C., Rehemtullah, A., Bristol, J.A., and Kaufman, R.J. (1993). J. Biol. Chem., 268:8458-8465.

14. Watanabe, T., Nakazawa, T., Ikemizu, J., Nagahama, M., Murakami, K., and Nakayama, K. (1992). J. Biol. Chem., 267:8270-8274.

15. Willnow, T.E., Moehring, J.M.. Inocencio, N.M,, Moehring, T.J., and Herz, J. (1996). Biochem. J., 313:71-76.

16. Wise, R.J., Barr, P.J., Wong, P.A., Kiefer, M.C., Brake, A.J., and Kaufman, R.J. (1990). Proc. Natl. Acad. Sci. U.S.A., 87:9378-9382.

17. Leduc, R., Molloy, S.S., Thorn, B.A., and Thomas, G. (1992). J. Biol. Chem., 267:14304-14308.

18. Rehemtullah, A., Dorner, A.J., and Kaufman, R.J. (1992). Proc. Natl. Acad. Sci. U.S.A., 89:8235-8239.

19. Misumi, Y., Oda, K., Fujiwara, T., Takami, N., Tashiro, K., and Ikehara, Y. (1991). J. Biol. Chem., 266:1695416959.

20. Molloy, S.S., Thomas, L., Van Slyke, J.K., Stenberg, P.E., and Thomas, G. (1994). EMBO J., 13:18-33.

21. Shapiro, J., Sciaky, N., Lee, J., Bosshart, H., Angeletti, R.H., and Bonifacino, J.S. (1997). J. Histochem. Cytochem., 45:3-12.

22. Vidricaire, G., Denault, J.-B., and Leduc, R. (1993). Biochem. Biophys. Res. Comm., 195:1011-1018.

23. Vey, M., Schafer, W., Berghofer, S., Klenk, H.-D., and Garten, W. (1994). J. Cell Biol., 127:1829-1842.

24. Bosshart, H., Humphrey, J, Deignan, E., Davidson, J., Drazba, J., Yuan, L., Oorschot, V., Peters, P.J., and Bonifacino, J.S. (1994). J. Cell Biol., 126:1157-1172.

25. Moehring, J.M., and Moehring, T.J. (1983). Infect. Immun., 41:998-1009.

26. Inocencio, N.M., Moehring, J.M., and Moehring, T.J. (1994). J. Biol. Chem., 269:31831-31835.

27. Watson, D.G., Moehring, J.M., and Moehring, T.J. (1991). J. Virol., 65:2332-2339.

28. Inocencio, N.M., Moehring, J.M., and Moehring, T.J. (1993). J. Virol., 67:593--595.

29. Robertson, B.J., Moehring, J.M., and Moehring, T.J. (1993). J. Biol. Chem., 268:24272-24277.

30. Moehring, J.M., Inocencio, N.M., Robertson, B.J., and Moehring, T.J. (1993). J. Biol. Chem., 268:2590-2594.

31. Takahashi, S., Kasai, K., Hatsuzawa, K., Kitamura, N., Misumi, Y., Ikehara, Y., Mirakami, K., and Nakayama, K. (1993). Biochem. Biophys. Res. Comm., 195:10191026. 
32. Takahashi, S., Nakagawa, T., Kasai, K., Banno, T., Duguay, S.J., Van de Ven, W.J.M., Murakami, K., and Nakayama, K. (1995). J. Biol. Chem., 270:2656526569.

33. Spence, M.J., Sucic, J.F., Foley, B.T., and Moehring, T.J. (1995). Somat. Cell Mol. Genet, 21:1-18.

34. Barr, P.J., Mason, O.B., Landsberg, K.E., Wong, P.A., Kiefer, M.C., and Brake, A.J. (1991). DNA Cell Biol., 10:319-328.

35. Creemers, J.W.M., Roebroek, A.J.M., Van den Ouweland, A.M.W., van Duijnhoven, H.L.P., and Van de Ven, W.J.M. (1992). Mol. Biol., 11:127-138.

36. Misumi, Y., Sohda, M., and Ikehara, Y. (1990). Nucleic Acids Res., 18:6719.

37. Korner, J., Chun, J., O'Bryan, L., and Axel, R. (1991). Proc. Natl. Acad. Sci. U.S.A., 88:11393-11397.

38. Roebroek, A.J.M., Creemers, J.W.M., Pauli, I.G.L., Kuriz-Dumke, U., Rentrop, M., Gateff, E.A.F., Leunissen, J.A.M., and Van de Ven, W.J.M. (1992). J. Biol. Chem., 267:17208-17215.

39. Roebroek, A.J.M., Creemers, J.W.M., Pauli, I.G.L.,
Bogeart, T., and Van de Ven, W.J.M. (1993). EMBO J., 12: $1853-1870$.

40. Van den Ouweland, A.M.W., van Duijnhoven, H.L.P., Keizer, G.D., Dorssers, L.C.J., and Van de Ven, W.J.M. (1990). Nucleic Acids Res., 18:664.

41. Laemmli, U.K. (1970). Nature, 227:680-685.

42. Creemers, J.W.M., Siezen, R.J., Roebroek, A.J.M., Ayoubi, T.A.Y., Huylebroeck, D., and Ven de Ven. W.J.M. (1993). J. Biol. Chem., 268:21826-21834.

43. Creemers, J.W.M., Vey, M., Schafer, W., Torik, A.Y.A., Roebroek, A.J.M., Klenk, H.-D., Garten, W., and Ven de Ven, W.J.M. (1995). J. Biol. Chem., 270:26952702.

44. Schafer, W., Stroh, A., Berghofer, S., Seiler, J., Vey, M., Kruse, M.-L., Kern, H.F., Klenk, H.-D., and Garten, W. (1995). EMBO J., 14:2424-2435.

45. Takahashi, S., Nakagawa, T., Banno, T., Watanabe, T., Murakami, K., and Nakayama, K. (1995). J. Biol. Chem., 270:28397-28401.

46. Voorhees, P., Deignan, E., van Donselaar, E., Humphrey, J., Marks, M.S., Peters, P.J., and Bonifacino, J.S. (1995), EMBO J., 14:496! -4975. 